was found to have hepatosplenomegaly which had first been noted in 1958. A liver biopsy showed the pathognomonic features of PBC with bile-duct destruction, proliferation of the bile ductules, granulomata and an inflammatory cell reaction (Scheuer, 1967) (Figs 1 and 2). At that time the total bilirubin was $9 \mu \mathrm{mol} / 1$, alkaline phosphatase $8 \mathrm{KAu} . / 100 \mathrm{ml}$ (upper normal limit $17 \mathrm{KAu}$.), alanine aminotransferase $95 \mathrm{u}$. (normal range, 4-17 u.), aspartate aminotransferase $168 \mathrm{u}$. (normal range 3-12 u.), IgM $2.8 \mathrm{~g} / 1$ (normal range $0 \cdot 3-2.0 \mathrm{~g} / \mathrm{l}$ ), mitochondrial antibodies were present in a titre $>1 / 1280$, positive bile canaliculi antibodies, negative smooth muscle antibodies and negative hepatitis-associated antigen. A wedge biopsy performed at laparotomy confirmed the diagnosis of PBC.

She remained well until 1970 when she developed diabetes mellitus and pancytopenia with a hypercellular bone marrow ascribed to hypersplenism. In 1975 she was admitted with ascites. At that time she was deeply pigmented but anicteric and without pruritus. A repeat liver biopsy showed progression of her PBC to a stage 4 cirrhosis (Scheuer, 1967). She responded to diuretics, but in 1976 she was readmitted with a haematemesis and died. Although a barium swallow had shown oesophageal varices, the cause of her haematemesis was not determined and no post-mortem examination was allowed.

Her alkaline phosphatase and 5-nucleotidase levels remained normal throughout her illness. Thus the alkaline phosphatase was $8 \mathrm{KAu}$. in 1963, 8 in 1967, 14 in 1970, 8 in 1975 and $11 \mathrm{KAu}$. in 1976. On electrophoresis the alkaline phosphatase was predominantly of hepatic origin with a minor component showing the mobility of the bone isoenzyme.

\section{Discussion}

This case has several unusual features. Despite evidence of progressive disease she had a prolonged survival without jaundice or pruritus. Zeegen et al., (1969) found that patients can develop PBC and portal hypertension without the classical symptoms of PBC. However, the alkaline phosphatase was raised in every case.

It has been postulated (Schaffner, 1975) that the raised alkaline phosphatase is due to bile regurgitation into the portal tract tissues through damaged ducts. In their review, Sherlock and Scheuer (1973) reported just two patients, both discovered incidentally, who had an initial alkaline phosphatase of less than $20 \mathrm{KAu}$., but no follow-up was recorded.

The present patient had a persistently normal alkaline phosphatase until her death and is believed to be the first such case reported. This underlines the lack of specificity of biochemical tests and, while histology is often not diagnostic (Scheuer, 1967), it emphasizes its value in diagnosing the disease.

\section{Acknowledgments}

I thank Dr R. I. S. Bayliss for permission to report this case and Professor Peter Scheuer for reviewing the histology.

\section{References}

SCHAFfner, F. (1975) Primary biliary cirrhosis. Clinics in Gastroenterology, 4, 351.

Sherlock, S. \& Scheuer, P.J. (1973) The presentation and diagnosis of 100 patients with primary biliary cirrhosis. New England Journal of Medicine, 289, 674.

SCHeuer, P.J. (1967) Primary biliary cirrhosis. Proceedings of the Royal Society of Medicine, 60, 1257.

Zeegen, R., Stansfield, A.G., Dawson, A.M. \& Hunt, A.H. (1969) Bleeding oesophageal varices as the presenting feature in primary biliary cirrhosis. Lancet, ii, 9 .

\title{
Gastro-colic fistula secondary to benign gastric ulceration
}

\author{
ROY TAYLOR \\ M.B., Ch.B., B.Sc. (Hons.) \\ Royal Infirmary, Edinburgh
}

\begin{abstract}
Summary
An 80-year-old woman developed osteoarthritis of the knees as a complication of her obesity. Indomethacin treatment precipitated gastric ulceration, which led to the formation of a gastro-colic fistula.
\end{abstract}

GASTRO-COLIC fistula is a rare condition and, unlike gastro-jejuno-colic fistula which usually occurs secondary to partial gastrectomy, is most often a complication of invasive gastric or colonic carcinoma (Cody et al., 1975). Other possible causes include 
Crohn's disease, intra-abdominal abscess and tuberculosis. The following report describes a case of gastro-colic fistula resulting from a benign gastric ulcer.

\section{Case report}

An 80-year-old woman was admitted to hospital following several haematemeses. She gave a 6-month history of intermittent vomiting after meals. The vomitus had initially consisted of unaltered food only, but later contained 'coffee ground' material and occasional streaks of fresh blood. One week before admission small amounts of fresh blood were passed per rectum followed by frequent melaena stools. At this point the vomitus became foul-tasting and her husband complained that her eructations made a foul smell in the room. Over the 6-month period she had lost $20 \mathrm{~kg}$ in weight but, apart from general malaise, there were no other associated symptoms. Her only significant past history was that of osteoarthritis affecting both knees for which she had been taking indomethacin $(50 \mathrm{mg}$, b.d.) for 5 years.

Although only $1.35 \mathrm{~m}$ tall she was grossly overweight at $85 \mathrm{~kg}$. She was pale and looked generally unwell. There was tenderness on palpation with associated guarding in the left hypochondrium. Examination was otherwise normal.

$\mathrm{Hb}$ was $10 \cdot 8 \mathrm{~g} / \mathrm{dl}$, with a microcytic, normochromic picture and ESR (Westergen) of $77 \mathrm{~mm}$ in the first hour. Blood urea was slightly elevated at $10.8 \mathrm{mmol} / \mathrm{l}$ and serum potassium low at $3.3 \mathrm{mmol} / \mathrm{l}$. Iron deficiency was confirmed with serum iron of $8 \mu \mathrm{mol} / \mathrm{l}$. and total iron binding capacity of 61 $\mu \mathrm{mol} / \mathrm{l}$. Faecal occult blood was positive. Barium meal was performed because of the high possibility of gastric carcinoma, but this demonstrated a gastrocolic fistula with no evidence of tumour or other abnormality.

After blood transfusion and fluid and electrolyte replacement, laparotomy was carried out. This showed the transverse colon to be adherent to the greater curvature of stomach by an area of dense fibrous thickening and, on opening the stomach, that an underlying deep ulcer crater was present. The connection was completely excised and stomach and colon separately closed. On histological examination the gastric ulcer was benign with evidence of focal haemorrhage and a granulation tissue-lined fistula led from the base of the ulcer through to normal colonic mucosa.

After a difficult postoperative period she made a complete recovery and was very well at follow-up 6 weeks later.

\section{Discussion}

Indomethacin is a well recognized cause of benign gastric ulceration (Boardman and Hart, 1967) and a common site for such ulcers is the greater curvature of stomach (Emmanuel and Montgomery, 1971). It is suggested that in the present case an indomethacininduced ulcer underwent localized perforation causing a fistulous connection to transverse colon. Such painless perforation is uncommon but not unknown (Haubrick, 1974). Diagnosis was confirmed by barium meal although this is possible in only $25 \%$ of cases of gastro-colic fistula, barium enema being the investigation of choice (Thoeny, Hodgson and Scudamore, 1960).

\section{Acknowledgments}

I am grateful to Dr R. F. Robertson and Mr A. J. Duff for permission to report this case.

\section{References}

BoARdMaN, P.L. \& HaRT, F.D. (1967) Side efrects of indomethacin. Annals of the Rheumatic Diseases, 26, 127.

Cody, C.H., Divinceti, F.C., Cowick, R.R. \& Mahanes, J.R. (1975) Gastrocolic and gastrojejunocolic fistulae: report of twelve cases and review of the literature. Annals of Surgery, 181, 376.

EMMANUEL, J.H. \& MONTGOMERY, R.D. (1971) Gastric ulcer and the anti-arthritic drugs. Postgraduate Medical Journal, 47, 227.

HAUBRICK, W.S. (1974) In: Gastroenterology, Vol. I (Ed. by Bockus, H.L.), p. 737. Philadelphia.

Thoeny, R.H., Hodgson, J.R. \& Scudamore, H.H. (1960) The roentgenological diagnosis of gastrocolic and gastrojejunocolic fistulas. American Journal of Roentgenology, 83,876 . 